\title{
EFFECTS OF A THIN LAYER ON REFLECTANCE AND REMOTE-SENSING REFLECTANCE
}

\author{
By A.A. Petrenko, J.R.V. Zaneveld, \\ W.S. Pegau, A.H. Barnard \\ and C.D. Mobley
}

$\mathrm{O}_{\mathrm{r}}$ holds the promise of determining biological and optical properties globally. Much research has been carried out on the inversion of the spectral radiance signals detected by satellite. However, almost all inversion algorithms are based on the assumption of a homogeneous ocean. How do thin layers of particulate matter affect the reflectance of the ocean? A thin layer exhibits increases in absorption and scattering parameters (inherent optical properties, IOPs) (Preisendorfer, 1961) compared with surrounding waters. These increases are due primarily to phytoplankton and in a lesser degree to dissolved organic matter.

It is intuitive that the deeper a thin layer is in the ocean. the smaller its influence on the reflectance at the surface. It is also intuitive that the thinner the layer, the less change in reflectance. It is perhaps not as obvious that, under certain circumstances, the thin layer can have no overall effect on the reflectance even if its absorption and scattering coefficients are an order of magnitude larger than the coefficients of the surrounding water. In effect. the layer may be invisible to remote sensing, even though it has significantly higher inherent optical properties than the surrounding water. This paper will address these issues and provide some examples of the effect of an idealized thin layer on reflectance.

Algorithms have been developed to derive the concentration of chlorophyll in

A.A. Petrenko, Dept. of Ecology. 300 Desmond Dr.. PO Box 47710. Olympia, WA 98504-7710. USA. Present address: LOB-UMR 6535, Centre d'Oceanologie de Marseille, Campus de Luminy. 13288. Marseille-Cedex 09, France. J.R.V. Zaneveld. W.S. Pegaw, A.H. Barnard. COAS, 104 Admin. Bldg.. Oregon State University, Corvallis, OR 97331. USA. C.D. Mobley, Sequoia Scientific, 9725 SE 36th St., Suite 308. Mercer Island. WA 98040. USA. the ocean from surface irradiance reflectance ( $R$ ) or remote-sensing reflectance (Rrs). Such algorithms were based on the assumption that reflectance of a stratified ocean was equal to the reflectance of a homogeneous ocean with a phytoplankton concentration equivalent to the depth-weighted average of the real phytoplankton concentration profile (Gordon and Clark, 1980). This was later proved to be true only when the absorption coefficient (a), the scattering coefficient (b). and the chlorophyll concentration all covary with depth (Gordon, 1992). Thin layers could affect $R$ and Rrs if their IOPs do not covary with depth.

Elsewhere in this volume, Zaneveld and Pegau (1998, this issue) have shown a simple two-flow model for the reflectance of a stratified ocean. Their equation (8) explains the phenomena mentioned above. The ocean is assumed to consist of N layers. Each layer is characterized by its "inherent reflectance" defined as the reflectance it would have if the layer were infinitely thick. The contribution of the layer to the overall reflectance of the ocean depends on the inherent reflectance of the layer weighted by factors proportional to the depth and thickness of the layer. A deeper, thinner layer contributes less to changes in $\mathrm{R}$ than a shallow, thick layer. However, equation (8) in Zaneveld and Pegau also shows that, if all layers have the same inherent reflectance, the reflectance of that stratified ocean is indistinguishable from the reflectance of a homogeneous ocean. The inherent reflectance does not necessarily change if the IOPs change in absolute value. The inherent reflectance is often expressed as $0.33 \mathbf{b}_{h} / \mathbf{a}$ (Morel and Prieur. 1977). where $b_{b}$ is the backscattering coefficient. If $b_{h} / a$ is constant, then even a layer with very high IOP can have the same inherent re- flectance as one with low IOP. If we were to insert a thin layer in a homogeneous ocean, the layer would influence the reflectance at the surface only if its inherent reflectance was different than the reflectance of the water it replaced.

We will illustrate these effects with some examples based on in situ measurements. A thin layer, observed in East Sound, Orcas Island, WA, was characterized by locally higher IOPs. The observed thin layer had significant vertical structure within it (Fig. 1). The IOPs did not covary with depth; the scattering to absorption ratio fluctuated significantly both in the thin layer compared with the rest of the water column and within this layer. To estimate how reflectances depend on the depth and thickness of this observed thin layer, it was decided to model this feature with an idealized thin layer. The inherent optical properties of the idealized thin layer were chosen on the basis of the optical properties measured in situ. $\mathrm{R}$ and Rrs were evaluated using the Hydrolight numerical radiative transfer model (Mobley, 1994). Changes of $R$ and Rrs in the presence of the thin layer were compared with a homogeneous water column. The depth and thickness of the idealized thin layer were then varied in order to estimate their influence on $\mathrm{R}$ and Rrs.

\section{Methods}

Absorption and scattering coefficients were derived from in situ measurements collected with an absorption and attenuation meter at nine wavelengths (ac-9: WETLabs, Inc). The measurements were taken on 1 June 1996 in East Sound, a fjord on Orcas Island. WA in Northern Puget Sound (Hanson and Donaghay. 1998, this issue). Values of absorption and scattering of the idealized thin layer 


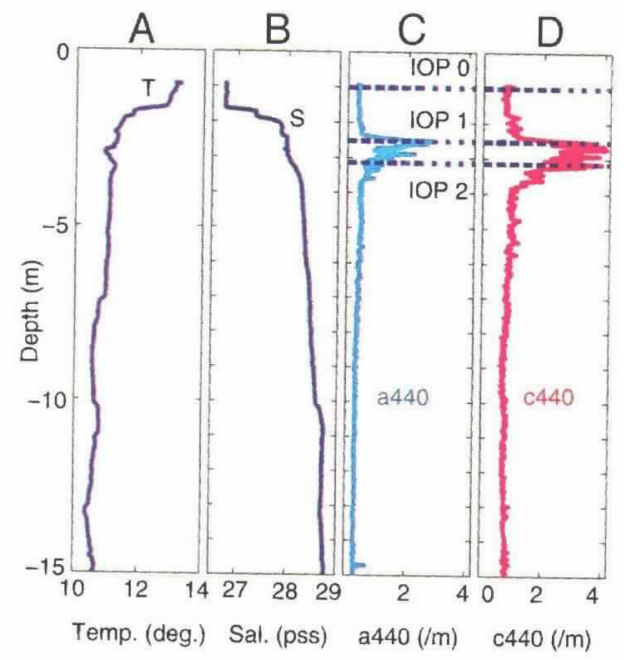

Fig. 1: Vertical profiles of (A) temperature, $(\boldsymbol{B})$ salinity, $(\boldsymbol{C})$ absorption, and $(\boldsymbol{D})$ beam attenuation coefficients at $440 \mathrm{~nm}$. IOP 0 corresponds to the measurements taken around $1 \mathrm{~m}, I O P 1$ to those collected in the shallower part of the thin layer, and IOP 2 to those collected in the deeper part of the feature.

were represented by the average values obtained within the in situ thin layer. Two extreme cases could be distinguished within the observed thin layer: 1) a low ratio of scattering to absorption $(\mathrm{b} / \mathrm{a}=0.11)$ at $2.5 \mathrm{~m}($ IOP 1) and 2) a high ratio of scattering to absorption (b/a $=4.45)$ at $3.1 \mathrm{~m}$ (IOP 2; Figs. 1 and 2). For the water column outside the thin layer, the average values of the absorption and scattering coefficients around 1 $m$ depth were used (IOP 0; Fig. 1). The average measured spectral values of a and $\mathbf{b}$ of these three cases (IOPs 0,1 , and 2) were splined over the visible spectra every $10 \mathrm{~nm}$. Basic boundary conditions were applied to force the spline functions; the a values were equal to the pure water value at $700 \mathrm{~nm}$, and the $b$ values were chosen at 400 and $700 \mathrm{~nm}$ by linear extrapolation (Fig. 2, A and B). A Raleigh phase function was used for the scattering due to the pure water, and an average of three Petzold phase functions (Petzold, 1972; Mobley et al., 1993) was used for the particulate scattering. The ratio of backscattering to absorption $\left(\mathrm{b}_{\mathrm{b}} / \mathrm{a}\right)_{\mathrm{i}}(\mathrm{i}=0,1$, and 2$)$ was calculated for the three basic IOP cases using the $b_{b} / b$ ratios for the Petzold volume scattering function. $\left(b_{b} / a\right)_{2}$ was higher than $\left(b_{b} / a\right)_{0}$ and $\left(b_{b} / a\right)_{1}$ throughout the visible spectrum; $\left(b_{b} / a\right)$ was lower (higher) than $\left(b_{b} / a\right)_{0}$ for wave- lengths shorter (longer) than $600 \mathrm{~nm}$ (Fig. 2C).

$\mathrm{R}$ and Rrs were estimated with the Hydrolight numerical radiative transfer model (Mobley, 1994). We used the following set of assumptions in the model: horizontally homogeneous ocean, real sky radiance distribution, sun at $45^{\circ}$ from the zenith, plane air-water interface (no wind), and no internal sources of light. For this study, the model was run with different permutations: varying the IOPs of the thin layer (IOPs 1 or 2), the thickness of the thin layer $(10 \mathrm{~cm}$ to $1 \mathrm{~m})$, and its position in the water column (surface to $19-20 \mathrm{~m}$ depth). In all cases, the rest of the water column was homogeneous (IOP 0 ) and infinitely deep.

\section{Results}

When a thin layer of IOP 1 is added to the homogeneous (IOP 0) water column, the reflectance is referred to as $\operatorname{R01}(i, j)$, where $i$ indicates the depth of the top of the thin layer (in meters) and $\mathrm{j}$ indicates the thickness of the thin layer (in meters). $\mathrm{R}$ for the homogeneous water column of IOP 0 is designated as R0.

\section{Idealized Thin Layer of 1-m Thickness}

Spectral variability of $R$ and Rrs. We examined the influence of the $b_{b} / a$ ratio on $\mathrm{R}$ and Rrs. When the thin layer was located at the surface, $\mathrm{R} 01(0,1)$ (i.e., reflectance with a $1-\mathrm{m}$ thick layer of IOP 1 at the surface) and $\mathrm{R} 02(0,1)$ were distinctly different from R0 (Fig. 3). Large changes in reflectances were due to the presence of the thin layer. Spectrally, $\mathrm{R} 01(0,1)$ ranged from 9 to $600 \%$ of $\mathrm{R} 0$. $\mathrm{R} 02(0,1)$ was higher than R0 throughout

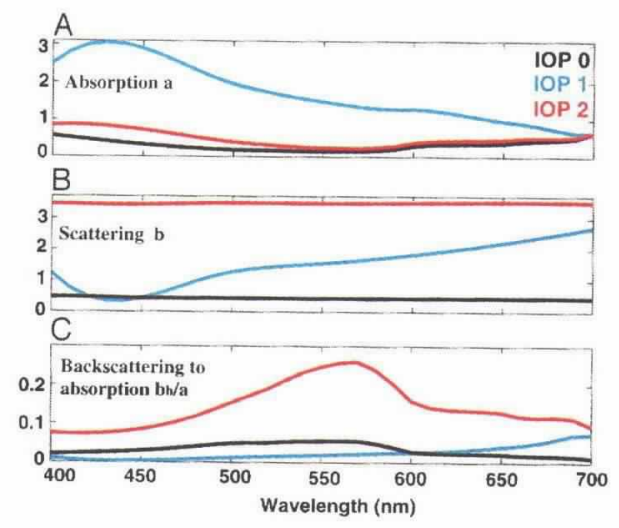

Fig. 2: Spectra of (A) absorption coefficient, $(\boldsymbol{B})$ scattering coefficient, and $(\boldsymbol{C})$ $b_{t} f a$. The color convention in the figures is black for IOP 0 , blue for IOP 1 , and red for IOP 2.

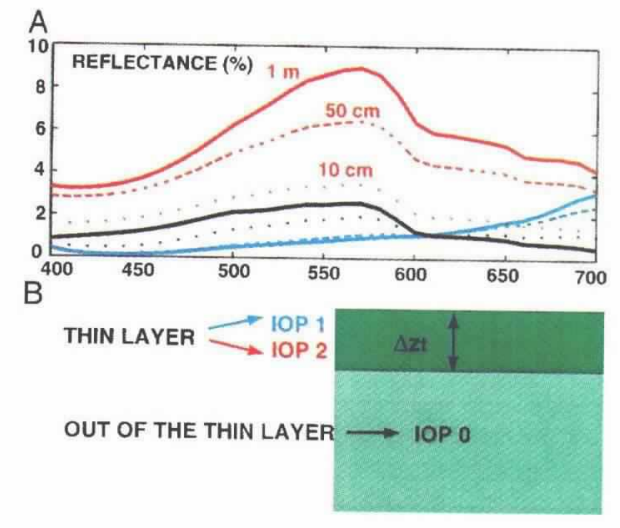

Fig. 3: Spectra of (A) R, (B) Rrs in percent. Solid lines are for RO (black), $R 01(0,1)$ (blue), and R02(0,1) (red); dashdot lines for R01 $(0,0.5)$ (blue) and $R 02(0,0.5)$ (red); and dotted lines for $R 01(0,0.1)$ (blue) and R02(0,0.1) (red).

the visible spectrum (Fig. 3), ranging from 290 to $800 \%$ of R0. R0, R01 $(0,1)$, and $\mathrm{R} 02(0,1)$ exhibited spectral shapes similar to the shapes of their respective $\mathrm{b}_{\mathrm{b}} / \mathrm{a}$ ratios (Figs. 2C and 3). The spectral variability of Rrs was qualitatively identical to that of $\mathrm{R}$ in the three cases.

Variability of $R$ and Rrs due to the vertical position of the thin layer. When the thin layer was deeper, $\mathrm{R}$ was closer to R0 (Fig. 4). For all wavelengths (only shown here for 410, 440, 520, and $550 \mathrm{~nm}$ ), R increased (decreased) exponentially to the homogeneous case R0, the deeper the thin layer of IOP 1 (IOP 2) was located (Fig. 4). Rrs followed the same trend as R (data not plotted). The convergence of Rrs to Rrs0 occurred when the thin layer was located at a deeper depth than that for which $\mathrm{R}$ converged to R0. This implies that Rrs was more sensitive to the presence of deep thin layers than $\mathrm{R}$.

Surface Thin Layer of Varying Thickness

While the thin layer was maintained at the surface, its thickness was diminished from $1 \mathrm{~m}$ to 50 and $10 \mathrm{~cm}$. The spectral shapes of both R and Rrs for the $50-\mathrm{cm}$ layer were similar to those for the $1-\mathrm{m}$ thick layer (Fig. 3). R01(0,0.5) ranged from 11 to $476 \%$ of R0. R01 $(0,0.5)$ was lower than R0 until $600 \mathrm{~nm}$ and higher than R0 at longer wavelengths. $\mathrm{R} 02(0,0.5)$ was higher than R0 throughout the visible spectrum (Fig. 3), with a range of $232-631 \%$ of R0. Both R01 $(0,0.5)$ and R02 $(0,0.5)$ still mirrored the shape of the $b_{b} / a$ relation of their respective thin layer (Fig. 2C). For a 10-cm-thick layer, the R spectra converged toward R0 (Fig. 3). 


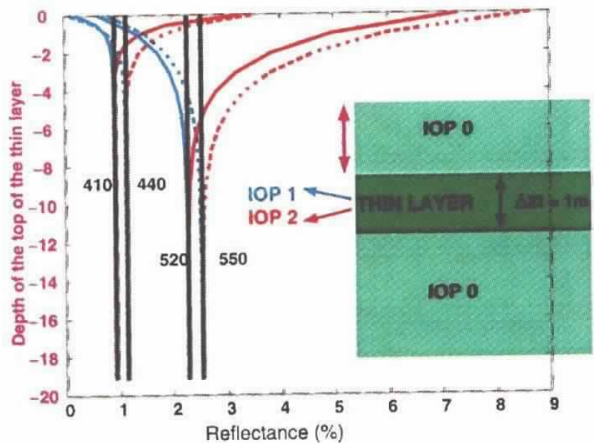

Fig. 4: Vertical profiles of $R$ in percent, at four wavelengths 401, 440, 520, and 550 $n m$, versus the depth at which the top of the thin layer is located (solid black lines for IOP 0 , blue lines for IOP 1, and red lines for IOP 2 results). $R 0$ results (black lines) are constant with depth since the thin layer is absent in these cases.

$\mathrm{R} 01(0,0.1)$ was $43-214 \%$ of $\mathrm{R} 0$, and R02 $(0,0.1)$ was $133-260 \%$ of R0. We observed the same pattern for Rrs.

\section{Discussion}

As discussed earlier in the paper, the contribution of a thin layer to the overall reflectance depends on the contrast of its inherent reflectance with that of the surrounding water. Indeed, percent changes in $\mathrm{R}$ and Rrs increased with increased absolute value of $\left(b_{b} / a\right)_{\text {thin layer }}-\left(b_{b} / a\right)_{\text {surrounding water }}$ and decreased the thinner the layers were and/or the deeper they were located. We can conclude that changes in reflectance depend to the first order on the changes in $b_{b} / a$, the optical thickness of the layer, and the depth of the layer.

Our simplified approach to this analysis did not include the effects of Raman scattering or fluorescence on reflectance. We chose the Petzold averaged phase function as a good approximation for the coastal waters of East Sound. It is possible that other phase functions could improve our estimates (see Mobley and Stramski 1997; Stramski and Mobley 1997), but these phase functions require detailed knowledge of species and size distributions of the particulate matter. We also ignored the effects of bubbles since we were assuming no wind, and we did not incorporate bottom effects or changing sun angle into our calculations. Any of these factors could alter the details of our modeling analysis, but would not alter the general conclusions we have presented.

In all cases of thin layers reviewed for this study, the shallower portion of the feature had lower backscattering to absorption ratio than the deeper part of the thin layer for wavelengths shorter than $550 \mathrm{~nm}$. Our results indicate that this type of thin layer will result in reduced reflectances and remote-sensing reflectances at short wavelengths. The presence of such thin layers will also impact the interpretation of ocean color algorithms based on reflectance ratios. It was also found that Rrs was more sensitive to the presence of a deep thin layer than R. R and Rrs differ by their numerator. This result indicates that the numerator of Rrs, the water-leaving zenith radiance just above the surface (Mobley 1994), captures more upwelling light for deep layers than the numerator of $\mathrm{R}$, the upwelling irradiance. This depth sensitivity of remotely sensed reflectance may result in an erroneous estimation of the chlorophyll concentration and the vertical structure of the water column and will need to be examined carefully in remote-sensing applications.

\section{Acknowledgements}

This study was funded by Office of Naval Research Environmental Optics Program, which also supported the development of Hydrolight. We thank Dariusz Stramski and Juli Berwald for their help, and Russ Desiderio for his review of the manuscript.

\section{References}

Gordon, H.R., 1992: Diffuse reflectance of the ocean: influence of nonuniform phytoplankton pigment profile. Appl. Opt., 31, 2116-2129. and D.K. Clark, 1980: Remote-sensing optical properties of a stratified ocean: an improved interpretation. Appl. Opt., 19, 34283430.

Hanson, A.K. and P.L. Donaghay, 1998: Micro- to fine-scale chemical gradients and layers in stratified coastal waters. Oceanography, 11, $10-17$.

Mobley, C.D., 1994: Light and Water: Radiative Transfer in Natural Waters. Academic, New York.

, B. Gentili, H.R. Gordon, Z. Jin, G.W. Kattawar, A. Morel, P. Reinersman, K. Stamnes and R.H. Stavn, 1993: Comparison of numerical models for computing underwater light fields. Appl. Opt., 32, 7484-7505.

and D. Stramski, 1997: Effects of microbial particles on oceanic optics: Methodology for radiative transfer modeling and example situations. Limnol. Oceanogr., 42, 550-560.

Morel, A. and L. Prieur, 1977: Analysis of variations in ocean color. Limnol. Oceanogr., 22 , 709-722.

Petzold, T.J., 1972: Volume scattering functions for selected ocean waters. Scripps Institution of Oceanography, La Jolla, Report SIO Ref. 72-78.

Preisendorfer, R.W., 1961: Application of radiative transfer theory to light measurements in the sea. Int. Geophys. Geod. Monogr., 10, 11-29.

Stramski, D. and C.D. Mobley, 1997: Effects of microbial particles on oceanic optics: a database of single-particle optical properties. Limnol. Oceanogr., 42, 538-549.

Zaneveld, J.R.V. and W.S. Pegau, 1998: A model for the reflectance of thin layers, fronts, and internal waves and its inversion. Oceanography, 11, 44-47. $\square$ 